\title{
Linguistic Precautions that to be Considered when Translating the Holy Quran
}

\author{
Ahmed Gumaa Siddiek (Corresponding author) \\ Shaqra University, Saudi Arabia \\ E-mail: aahmedgumaa@yahoo.com
}

Doi:10.7575/aiac.alls.v.8n.2p.103

URL: http://dx.doi.org/10.7575/aiac.alls.v.8n.2p.103
Received: 01/03/2017

Accepted: 06/04/2017

\begin{abstract}
The present study is an attempt to raise some points that should be considered when translating the Quranic Text into English. We have looked into some samples of translations, selected from well known English translations of the Holy Quran and critically examined them. There were some errors in those translations, due to linguistic factors, owing to the differences between the Arabic and the English Language systems. Some errors were due to the cultural background of the translator which intentionally or unintentionally has affected the translation. Many samples were discussed and suggestions for corrections were made. Then further recommendations were given to be used as guidelines for similar future attempts. We concluded that the simulation of old words in drafting a translation does not fit with the English language as a target language. As this use of archaic stylistics would lead to further complications, which makes the language of translation look strange and complicated
\end{abstract}

Keywords: Quranic Translation, Archaization, Muslim scholar, untranslatability, linguistic factors

\section{Introduction}

Translating the Holy Quran into another language is no longer a controversial issue, as most Islamic scholars have expressed a degree of permissibility of translating the Quranic Text into foreign languages. This is because the Islamic message is a global message not confined to one particular race or color; so the transferring of this message to NonMuslims is a practical need. It is as well a duty of every Muslim, to dispatch the Word of Allah to reach all mankind in their own languages. So if the is delivered in the right form then target receivers may have good understanding of Islam, with its great values and great teachings. The translation of the meanings of the Quran will serve this purpose.

The present study was originally a conference paper in (Arabic) written by Professor Abd Allah bin Hamad AlHumaidan and Dr. Abdul Jawad bin Tawfiq Mahmud; presented to the (Seminar of Translation of the Holy Quran: Evaluation of the past and plans for the future); that took place in $25 / 4 / 2002$. The conference was sponsored by King Fahd Complex for the Printing of the Holy Quran in Meddinah. All the papers in the conference were dealing with the issue of the translation of the meanings of the Holy Quran in foreign languages. The topic -as you can see- is of importance, as it deals with an issue of great interests to all Muslim communities. But all the papers were presented in Arabic, so I feel that the findings of this conference and other similar conferences will reach only a limited number of people who speak the Arabic Language, but the target reader will not find his/her way to the findings of such conferences; as the papers were not written in English or any other foreign language/s. We need to say that the target audience of the conference were/are the English speakers in general and the English translators of the Holy Quran in particular, who produced the translation in concern. My work here is to translate some of these papers into English that I may be able to serve the following purposes as:

1. To reflect the opinions and the points of views of Muslim scholars and Muslim Fuqha (فقه) about the translations made by some English translators and to see to what extent those translation fit and serve the purposes of conveying Allah's True Word to all human beings; through the reproduction of foreign language versions for the meanings of the Holy Book.

2. To establish a corpus of references that can serve academic purposes in the fields of the translation of the meanings of the Holy Quran in English. Because most of the responses and most of the critical efforts towards the translations of the meanings of the Holy Quran are written in Arabic, with scholarly professionalism to defend the Quran, but these efforts will not serve the Quran at large, as they do not speak directly to the target reader or translator in his/her own language. So the efforts will remain unexposed and will not reach the keen reader/s who would want to investigate the degree of correctness or incorrectness of these foreign translations of the Quranic text.

3. It is also my intention to defend the Islamic values, Islamic teachings and Islamic civilization from this severe attack from academic and no-academic individuals and organizations, who are trying hard to disgrace the Islamic Religion as a TRUE religion and an ideology adopted by millions of Muslims-all over the world-as a way of life and as an accepted code of good human behaviour. 
4. It is indeed my duty to defend the prophet of Islam Mohmmed bin Abdellah (peace be upon him) from the systematic work to disgrace his image (peace be upon him); as the messenger of Allah who carried his WORD to all mankind and as a legislator who explained and gave details about all Islamic rules and Islamic teachings; through his authenticated actions and sayings.

\section{Methodology}

The present study deals with certain linguistic precautions that need to be considered when translating the Holy Quran into English. We explored the impact of some translations on the ability of the target reader to fully assimilate the ideas and concepts carried by the translated text. The data was derived from different models of Quranic translations; but as there were too many translations of the Holy Quran into English, we have selected the following translations to serve our purpose:

\begin{tabular}{clc}
\hline $\mathbf{1}$ & J. M. Rodwell & $\mathbf{1 8 6 1}$ \\
\hline $\mathbf{2}$ & E. H. Palmer & 1880 \\
\hline $\mathbf{3}$ & M. Muhammad Ali & 1917 \\
\hline $\mathbf{4}$ & Y. Ali & 1934 \\
\hline $\mathbf{5}$ & R. Bell & 1937 \\
\hline $\mathbf{6}$ & A.J. Arberry & 1955 \\
\hline $\mathbf{7}$ & David N. Dawood & 1956 \\
\hline $\mathbf{8}$ & T. Irving & 1985 \\
\hline $\mathbf{9}$ & M. Khatib & 1986 \\
\hline $\mathbf{1 0}$ & Syed V. Ahmad & 1999 \\
\hline
\end{tabular}

This does not mean that these translations of the Quran into English are the only available translation. In fact, the number of these translations is growing every day. The selected translations were chosen for their quality of craftsmanship and to some extent for their authenticity.

\section{Archaization: Aping obsolete linguistic Style}

The process of archization is to simulate some linguistic styles, which is an old phenomenon not applicable only to the translations of Holy Quran into English; but it dates back to translators tendency to adopt old translation theories since the Victorian era, such as Carlyle (1795- 1881), Newman (1805- 55) and Morris (1834 - 96). Those theorists considered the commitment to the principle of old methods of the language of translation of the literal works; as the best direction. In this regard, we can mention Newman (1861), who believed that the translator should retain all the strange features that characterize the original language whenever possible.

Dumping in the use of old methods as such; is based on the belief that old methods can be seen as indication of language nobility and nobility of the translation as well. It is also claimed as a sort of mechanism that carries the old attributes of the language in terms of places and time.

Looking into the translations of the Holy Quran into English, we find that the most dumping in the use of abandoned techniques is clear in the translation of Yusuf Ali, and to a large extent in the translation of Pickthall and Arberry. Arberry for example, explained that the basic objective in his translation of the meanings of the Quran was to attain the maximum level of integrity in his translation to mimic the Quran rhetorical styles. But sticking to old techniques in the language of translation cannot be justified for the following reasons:

1. Adhering to old techniques and using old words in translation has nothing to do with the sanctity of the original text. So when translating the Quran into English, the language of the translation is no longer the original WORD of Allah Almighty, and no longer has the sanctity of the original text; because it is a mere human reproduction made by the translator. Therefore, the belief that, commitment to the old ways of translation would maintain the holy features in the language of the translation; is a mere misconception.

2. Sticking to the abandoned methods of translation, under the pretext of commitment to the principle of fidelity in transferring the source language; is in fact a betrayal to principles which are more important to the corpus of the translated text and its meaning.

3. Also sticking to the old methods is a betrayal to the ability of the target reader to absorb such a translation. It is no doubt that reaching the target reader through a simple and a clear method, is more important than sticking to formalities of old wording and structures.

4. The belief that the old techniques and the use of old words are indications of the nobility and advancement of the language of translation, is not warranted; as the primary function of the language of any translation is to convey the meanings and concepts contained in the source text and directed to the target reader.

5. We can add to that talking about the nobility of a language is not based on linguistic rules, because these concepts are relative and not subject to specific linguistic criteria.

\subsection{Difference of Language systems}

We should not forget - when talking about the issue of the commitment of using old words in translating the meaning of 
the Holy Quran into English-to refer to a set of fundamental differences between Arabic and English in terms of historical and social dimensions, which we believe are relevant to this case. These dimensions can be summarized as follows:

- The existence of old words and structures in the Arabic language is natural, especially in contexts and situations dealing with Islamic issues. These old structures and old words are in fact not completely deserted. And despite being linguistically old and archaic; they are still in circulation. We can find, for example, that members of any Muslim community, who are exposed to the Quranic text by listening or reciting it; would look to the ancient words and structures as quite a normal phenomenon.

- This is the truth about the use of old words and old structures in the context of the source language, but when they are transferred to the target language such as English, we can find that it is quite different; because the transferring of the meanings of the Quran to Old English, will not make the English text have features parallel to the attributes of the original Arabic text, especially in those particular attributes relating to the mechanism of exposure such as listening and reciting.

- The transferring of the meanings of the Quran to Old English, makes words and structures of old English look more exotic, more complex and more ahead of their counterparts in the source text.

- From historical linguistic point of view classical Arabic is actually an ancient language compared to the standard English-language. For example, we find that the Arab reader can understand an Arabic text written hundreds of years ago, while it is not the case in English, because archization is somewhat an inherent feature in classical Arabic.

- Accordingly, the old words and the old structures in the Quran somewhat seem familiar to the Arabic reader, whereas in the English language, the structures and the old words are not familiar to the modern English reader; as it will not be easy to the modern native English young person to understand the English texts which was written some hundred years ago, such as the poems of Chaucer or the tales of Canterbury, according to Altyb (2017, online).

- It is well known that linguistic duality (Diglossia) in the Arabic language is fixed and stable; that the rates of language change in classical Arabic is less than in their counterparts in the standard English, because the bulk of the output of this change is absorbed by the Arab dialects, which makes classical Arabic more stable and less variable than the standard English. So stability makes the use of old words and structures look natural in Arabic than in English.

In order to identify the extent of dumping in the simulation of old methods and old words we have gone through the following seven translations of the Qur'an by:
a) A. J. Arberry
b) J. M. Rodwell
c) M. M. Pickthall
d) M. Ali
e) A. Y. Ali
f) N. J. Dawood
g) T. B. Irving

By comparing these seven translations, it can easily be seen that some translators like T.B Irving and N.J Dawood were less adherent to old words and to abandoned techniques. We can also see that the language of the translation in Irving and David are smoother and less complicated than those translations made by Pickthall, Y. Ali , Arberry and Rodwell. This may be due to the fact that some of Muslims translators believe that the preservation of old words in translation is an indication of maintaining the sacredness of the source text- the Quranic text. (See the models of these seven translations in Appendix No. (1), where old structures are underlined.)

We concluded from the foregoing discussion that the simulation of old words in drafting a translation does not fit with the English language as a target language. As this use of archaic stylistics would lead to further complications, which makes the language of translation look strange and complicated. These complications will-of course-prevent the target reader from understanding the translated text. Therefore we support the direction taken by: T.B Irving and N.J Dawood, in terms of ranging away from the old techniques and adopting simplicity at both lexical and structural levels.

But strangely, the abandonment of the archaic methods and the use of old words in the language of the translation is often considered as resorting to vernacular, which is said to violate the source text. In fact these are the most important aspects of criticism addressed to the translation of Dawood and Irving. For example, we find in Dawood's translation of Surat "the unbelievers الكافرون", that the language of the translation adopted by him was described as mere spoken prose. In another study of the translation of the Quran entitled "Translating the Untranslatable": A Survey of the English Translation of the Quran", Kidwai (1987), described the language of the translation espoused by Irving, as not fitting 
the sanctity of the Quranic Text and its special style. This point can be evidenced by a commentary by Irving as saying that he had used a lot of American expressions that did not fit the sanctity of the language of the Quran and its unique style.

However, we believe that aiming for simplicity and avoiding old words and old structures, in the language of translation as Irving, who is an American Muslim, did is not at all inconsistent with the sanctity of the Quranic text and its sedate style. All that Dr. Irving did when making his translation, was his keenness to take into consideration the quality of the target reader-the young Americans in this case. See (Badr,1994) for further details.

Hence the adoption of such a style in Irving's translation fits the target reader and helps him/her to understand the message and concepts; and since the language of the translation serves this purpose, this we think is the most important and it must be taken into account when coining a language of a translation.

This adoption of simple style of translation has also been adopted by Dr. Syed Waqar Ahmed- a specialist in IT and computer sciences- in his translation of the Qur'an, which lasted fifteen years and issued in Malaysia in 1999, under the title of "Interpretation of the Meaning of the Glorious Qur'an: A Simplified Translation of the Qur'an for Young People. The Translator aimed to using simple words and structures; and ranged away from old and complex methods.

\section{Dumping in Literal translation}

Dumping in literal translation at the lexical level, as well as at morph-syntactic is one of the root causes that lead to semantic ambiguity in the translation of the Quran from Arabic into English. This can be ascribed to two different factors:

- The first is the linguistic differences between English and Arabic in terms of lexical, syntactic and morphological features. In addition to the pragmatic and contextual factors which may leave some impact on the Quranic style.

- The second factor is non- linguistic. It is about the translator's belief that the sanctity of the source text-as being the word of Allah Almighty-requires the translator to do his/her best to literally conveying the structural features of the source text to the target text. Then here comes the problem that because the translator thinks that $\mathrm{s} / \mathrm{he}$ has to deal with the Arabic compositional templates, as well as seeing the Arabic words as models that must be followed when translating the Quranic text into English.

This belief will naturally lead to dumping into literal translation, which will result in semantic ambiguity and structural complexities; that can prevent the reader to understand the purpose of the text. The negative role of the morphological features and the lexical semantic can black out the ability of the target reader to absorb the meanings and concepts of the translation of the Quranic Text. This point can be supported by Nida E. Nida (1964) when saying,"formal features like orthography, word formation, syntax etc. can contribute to overloading the communication thus increasing the level of unpredictability." The semantic Ambiguity caused by dumping into literal translation, can be classified into two types: lexical and structural levels

It should be noted that there might be some possibility that literal translation may lead to semantic ambiguity in the mind of the target reader. This largely depends on the structure of the text -the subject of translation. There are some Quranic verses which are so simple: in their structures at verbal lexical or structural levels. In such cases, literal translation will not lead to semantic ambiguity. There are other Quranic Verse, not only complicated in terms of structure, but also reflect concepts and cultural meanings quite different from those characterizing the target language. In this case the literal translation of such Verses may lead to semantic ambiguity.

For instance, Verses 62 and 63 of Surat (the Prophets: الأنبياء), the verse looks very simple at the lexical and structural levels. They are not carrying any implications that embody fundamental cultural differences between the source language culture and the culture of the target language. So the literal translation of these verses will not lead to any semantic ambiguity as can be seen below:

$$
\text { (الأنبياء:63-62) }
$$

This verses can be translated as follows:

(They said: Was it you who did this to our gods Abraham? He said, (No), but it was done by this one, their chief; so ask them if they can speak.)

It is clear that commitment to literal translation of those verses has not resulted in any degree of ambiguity in the translation. On the contrary, the literal translation of the first verse of Surat (Explanation:الشرح) can be even more likely to lead to semantic ambiguity in the mind of the target reader, given that the structure of this verse reflects linguistic and cultural variations between the source language and the target language, as will be seen below.

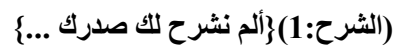

This verse can be translated as follows:

(Haven't We expanded for you your chest?

By investigating the views of some English speakers; they said that the translation of the verse in the manner described above; reflects semantic ambiguity in the mind of target reader. And for this reason, we find that many of the various translations such as of Pickthall, Yusuf Ali and Dawood- despite their formal differences in the translation of this verse - they reflect the fact that the literal wording leads to semantic ambiguity in the target reader's mind, as it is evident in the following models: 


Ali $\quad$ (ألم نشرح لك صدرك ...) Have We not expanded thee thy chest?

\begin{tabular}{lll}
\hline Pickthall & (ألم نشرح للك صدرك $\quad$ Have We not caused thy bosom to dilate? \\
\hline Dawood & (ألم نشرح للك صدرك ... & Have We not lifted up your heart? \\
\hline
\end{tabular}

It is clear from the translations of this verse the similarity between Yusuf Ali and Pickthall in using old techniques and old words; in reverse to Dawood's translation which is in line with what we will refer to in the next section of this study.

\subsection{Synthetic-semantic ambiguity}

The semantic ambiguity at synthetic structural level is a common feature in the language of the translation of the Holy Quran. Perhaps the basic reason for this is the translator's overlooking to normalize linguistic features that have no counterparts in the target language. AlGergani:(1969) pointed to a set of language features-that characterize Arabic language, and that the translator should consider adjusting when translating from Arabic into other languages. Most of those features mentioned by Al-Gergani are: definiteness and indefiniteness, ellipsis, repetition, $\underline{\text { unspecification }}$ and case ending.

But if we look in the English language, we will find that most of the features mentioned by AlGergani are not common in the English language. So this will pave the way to semantic ambiguity in translating from Arabic into English, especially if the translator committed himself/herself to literal language templates in the source language.

When translating the Holy Quran into English, it becomes more complicated, as a lot of translators are keen about literal wordings and linguistic structures. Translators also are keen about the arrangement of verses without taking into consideration the peculiarities of the target language. They believe that the sanctity of the Quranic text requires literal translation of all the linguistic elements that make up the text. In this case this type of translation will definitely lead to semantic ambiguity, as we will show below by viewing some sample translation of verse 28 in Surat:(Fater)

\begin{tabular}{|c|c|c|}
\hline & Translator & English Translation \\
\hline 1 & Arberry & Only those of His servants fear God who have knowledge. \\
\hline 2 & Ali & Those truly fear God, among His servants who have knowledge. \\
\hline 3 & Pickthal & The erudite among His bondsmen fear Allah alone. \\
\hline
\end{tabular}

But before analyzing these translations, we need to point to a linguistic feature in which Arabic language differs from English. This linguistic feature is closely related to semantic ambiguity in the translation of this verse. This feature is attributed to the nature of the word order. The Arabic language is characterized by a high degree of flexibility in the arrangement of words within the sentence, because the Arabic language is one of the languages that rely on case endings, and as a result we find that the (preposing التقايم and postposing والتأخير) are common techniques in the Arabic language, because the combining diacritical mark is going to have a combining diacritical function; and this combining diacritical mark is not necessarily located there in the sentence due to its syntactic position.

For example, in the verse mentioned above we find that word "Allah-God " Almighty carries the mark of case ending feature of the objective case mark -Alfatha- which functions as an evident that the word (Allah) here in this context is an (OBJECT) to a verb despite of its preposing position, as the word (Allah) comes immediately after the verb; and in this case it will look as if it is the (SUBJECT) of the sentence, but in fact, it is the (OBJECT) of the sentence. But in English, the style of (preposing) is not common - except in some cases of poetry- because the English word order rules do not depend on combining diacritical endings as in Arabic.

So if the translator is not aware of the differences between the source and target language systems, s/he will convey the same (preposing) style from the source language to the target language. This literal quoting will consequently lead to semantic ambiguity. Therefore, in Arberry's translation, we find that the phrase (who has knowledge) refers to the word (God), because the translator did not take into account the differences between the two language systems in terms of the word order. In the same line we find the same ambiguity in the translation of Yusuf Ali, as no reader can understand the phrase (who have knowledge); as where it relates to; does it relate to (God) or to does it refer to the phrase (His servants)?

But in Pickthall's translation, the problem lies with the word alone. It is true that there is an implied exception in the verse, but the correct term is only rather than alone and its appropriate location is to come before the word (erudite), as pointed by Al-Tayeb (1985:294). In fact we agree with the translation, however, we believe that it is more appropriate for this verse to be translated as follows:

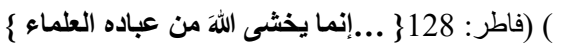

(From among His servants, only those who have knowledge fear Allah.) 
By Lexical semantic ambiguity we mean here the reader's inability to reach an objective meaning to the specific lexical item from among the different meanings of the word or the lexical unit. In translating the words of the Quran we must distinguish between two types of context, namely the explicit context and implicit context. By the explicit context we mean the context, through which the reader can determine the meaning of lexical unit or word. The implicit context includes the semantic and the interpretational system of the lexical unit-the sura in this case-that includes this lexical item or word which contains semantics concepts, interpretations and explanations. In other words, the scope of the implicit context verse in which the word is given will be the entire Surah. For example, we find that the word "ornaments:زينة" appeared in seven verses as well as the word "scriptures:" الزبر:" etc... But every lexical unit or word has certain frequency rate in multiple contexts; therefore, each word will have a different meaning depending on the context. So when translating into English, the translator must identify the different meanings of the word in every context so that s/he can find the English word that fits in each specific context; since it is mostly not possible to find one English word that fits different contexts in the Arabic language all the time. We cannot fail here to refer to the semantic vagueness that could result from the translation of two categories of inseparable lexical units (which used together) as "Collocations". See (El-Tayeb,1985: 285-286) for more details. The problem in translating "collocations" mostly sharply varies in language of literal translations of such terms, therefore, the literal translation of these words inevitably lead to semantic ambiguity. For example in Arabic there is a lexical correlation between the word "eat" and the word "money" this combination took place in many verses of the Quran, including:

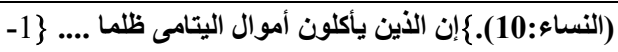

$$
\begin{aligned}
& \text { (التوبة:34). إن كثيرا من الأحبار والرهبان ليأكلون أموال الناس ... 3 (2- } \\
& \text { (البقرة:188). }
\end{aligned}
$$

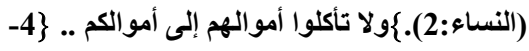

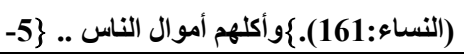

However, in other languages, such as English for example - there is no conjunction between "eat" and "money", and therefore we do not find in English such expressions as:

\begin{aligned} & \hline To eat money \\ & \hline To eat the wealth of others \\ & \hline To other's Property \\ & \hline\end{aligned}

Accordingly, we find that the literal translation of these Arabic expressions into English is not acceptable; however, many translations of the Quran did not take that into consideration, but literally relayed these expressions into the English language. For example, in Pickthall's translation as well in the translation of Yusuf Ali literal expressions were quoted by using (eat up property), while Dawood used (consume goods); where Arberry used (usurp property). We can notice that the common denominator among these translations is the commitment of the three translators to literal translation, although a minor degree of difference can be noticed.

But the question that arises now is about the best alternative as a translation of these expressions, and the answer to this, we can say: If we take into account the context in which these expressions can be seen, then the word "eat" in these verses is not "the action of eating or concept of consumption' at the literal level. But it means (a person who takes over something which is not his/her own but of others), therefore, we propose that the English translation of this expression in the referred five verses is to be as in the first translation of the first verse that reads:

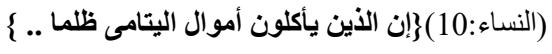

(Those who unjustly take possession of the orphans' properties...)

But we do not claim that these proposed translation is a unique model, but what we mean to address the problem of the translation of such expression. (El-Hassan, et al 1989)

\section{Conclusion}

The present study included the presentation and analysis of some linguistic precautions that needs to be considered when someone intends to translate the Holy Quran into English or any other foreign language. A full consideration should be taken about the impact of such translation on the target reader. Our data included samples of translations of the Holy Quran into English like: (A.Arberry 1955, J. Rodwell 1861, M.Pickthall 1930, M.Ali 1917, Y.Ali 1934, N.Dawood 1956, B.Irving 1985 and S.Ahmad 1999). The study has focused on two axes: the first is about the Archization of using old language techniques in the translation of the Holy Quran. The second relates to dumping into literal translation. As for the first part we have come to the conclusion that: 
- $\quad$ sticking to old methods,

- and using old words when translating the Quran into English-by arguing that it is a symbol of classical language,

- $\quad$ or arguing that this style would add strength to the principle of honesty in conveying from the source language; all of those points can actually be considered as clear betrayal of the real principles, which are more important, as they are concerned with the core of the translated text and its meaning. Those principles that are also concerned with the ability of the target reader to absorb the translated text. So these goals are more important than sticking to archaic style of language formalities rather than functions. As for the second part we concluded that:

- Adhering to literal translation of the source text, on the grounds that it preserves the sanctity of the Quranic text- is an unjustified belief, because such trend involves confusion between the source text which is the Word of Allah and the translated text which is mere a human-make.

- Thus, the pursuit of delivering the meanings of the text to the target reader in familiar language templates, without ambiguity, is more important, than clinging to the literal text of the source.

- The present study also showed that dumping in the literal translation when translating from Arabic into English ignores the substantial differences of Arabic and English language systems such as "word order", "diacritical cases", "definiteness", "indefiniteness", "proposing" and "preposing" which all lead to semantic ambiguity in the language of translation at lexical and structural levels.

- Through this presentation and analysis of the problem of the simulation of old techniques and dumping problem in old styles; and according to the data used in this present study, we have made clear that the translation of T.Irving and N.Dawood are more acceptable as they are less in terms of sticking to the use of archaic techniques and words in their translations.

- On the contrary A.Arbery, J.Rodwell, M.Pickthall and Yusuf Ali's translations are replete with old techniques and literal commitment of old ways as it is evident in the appendix (1).

In conclusion, we need to point out that the Quran linguistically addresses/addressed the Arabs in their own language that includes unique mechanisms, structures, meanings and ideas. The Quran is a linguistic miracle in its Arabic Context. So if it is translated into another language - as, for example, English - it is impossible to transfer those features and attributes, despite the translator's keenness to clinging and sticking to literal wording and literal compositions and despite his/her full mastery of the Arabic language with its own secrets.. Therefore, the claim that a translator can convey this linguistic miracle into another language is incompatible with the fact that; the Quranic Text is a miracle and a challenge as well. The untranslatability of the Quran is beyond doubts, but we can aim to a translation that can make some interpretations and explanations of the meanings of the Quranic Text, which can help the target reader to understand the Quranic Discourse.

\section{References}

Ahmad, S. V. (1999). Interpretation of the Meaning of the Glorious Qur'an: A Simplified Translation of the Qur'an for Young People. TR Group of Company Kuala Lumpur, Malaysia.

Al-Gergani, Abdulqadr. 1969. dalayil al'iiejaz. misr: Egypt, Cairo.

Al-Tyb, Al-Majeed. 2017. (Tamaiz Lughat Al-Quran)

https://www.youtube.com/watch?v=7rcu4Npq13o. on line, retrieved on 14-3-2017

Bader, B. (1994). A Critique of Six English Translations of a Quranic Text. Islamic Culture: An English quarterly Published by the Islamic Culture board, Hyderabad, India vol. LXIII, No. 3: 1-12)

El- Hassan, S. and Al-Said, M. (1989). "Lexical Issues in Translating the Qura'n into English: Obstacles and Suggested Solutions.” International Journal of Islamic and Arabic Studies, Bloomington, Indiana, 6(2), 45-57.

El-Tayeb, K. (1985). Principles and Problems of the Translation of Scriptures: the Case of the Qur'an Ph.D Thesis, Temple University

Kidwai, A. (1987). Translating the Untranslatable; a Survey of English translations of the Quran (Published on the Internet at (http//www.soundvision. com/quran/English. Shtm/).

Newman, F. (1861). Homeric Translation in Theory and Practice. London and Edinburgh: Williams \& Norgate.

Nida, E. (1964). Toward a Science of Translating. Leiden: Brill.

Niaamathullah, A. (1999). Is there an ultimate Translation of the Quran (published on the Internet at http://leb.Net/pipermail/Lexington-net/1999- December/). 
These are some samples of the translations of the meanings of the Holy Quran from Surat (the unbelievers: الكافرون ). The old techniques and structures are underlined.

(a) A. J. Arberry, 1955: ترجمة آربري

\section{The Unbelievers}

In the Name of God, the Merciful, the Compassionate

Say: $\underline{O}$ Unbelievers

I serve not what you serve

And you are not serving what I serve,

Nor am I serving what you are served,

Neither are you serving what I serve,

To you your religion, and to me my religion!

\section{(b) J. M. Rodwell, 1861: ترجمة رودويل}

\section{The Unbelievers}

In the Name of God, the Compassionate, the Merciful

say: $\mathrm{O}$ ye Unbelievers!

I worship not that which ye worship,

And ye do not worship that which I worship;

I shall never worship that which ye worship,

Neither will ye worship that which I worship,

To you be your religion; to me my religion.

ترجمة بكثول:c M. M. Pickthall, 1930

\section{The Disbelievers}

In the name of Allah, the Beneficient, the Merciful

Say: $\underline{O}$ Disbelievers!

I worship not that which ye worship;

Nor worship ye that which I worship.

And I shall not worship that which ye worship.

Nor will ye worship that which I worship

Unto you your religion, and unto me my religion.

ترجمة محمد علي : (d) Muhammad Ali, 1917

\section{Al-Kafirun: The Disbelievers}

Say: $\underline{\mathrm{O}}$ disbelievers.

I serve not that which you serve.

Nor do you serve Him whom I serve.

Nor shall I serve that which ye serve.

Nor do you serve Him whom I serve,

For you is your recompense and for me my

Recompense 
ترجمة يوسف علي: (e) A. Yusuf Ali,1934)

Kafirun or Those who reject Faith

In the name of God, Most Gracious, Most Merciful

Say: $\underline{\mathrm{O} Y e}$

That reject Faith!

I worship not that

Which ye worship,

Nor will ye worship

That which I worship

And I will not worship

that which ye have been

Wont to worship

Nor will ye worship

That which I worship

To you be your way

And to me mine

\section{(f) N. J. Dawood, 1956:ترجمة داود}

\section{Unbelievers}

In the Name of Allah, the Compassionate, the Merciful

Say: "Unbelievers, I do not serve

what you worship, nor do you serve

what I worship. I shall never serve

what you worship, nor will you serve

what I worship. You have your own religion, and I have mine.

\section{ترجمة إرفنغ:1985 T. B. Irving,}

\section{Disbelievers (or Etheists)}

In the name of God, the Mercy giving, the Merciful

Say: $\underline{\mathrm{O}}$ disbelievers!

I do not serve what you serve

Nor are you serving what I serve!

I will not worship what you have worshipped,

Neither will you worship what I worship

You have your religion

While I have 